\title{
The effects of stimulus rotation and familiarity in visual search
}

\author{
ROBERT RAUSCHENBERGER \\ Siemens Corporate Research, Princeton, New Jersey \\ and \\ HENGQING CHU \\ Peking University, Beijing, China
}

\begin{abstract}
Rauschenberger and Yantis (2006) observed that an intersecting circle-line combination enjoyed significantly greater search efficiency when it was oriented to resemble a "Q" than when it was oriented so that the intersecting line was vertical (cf. Treisman \& Souther, 1985). Although a control experiment made it unlikely that the obliqueness of the line was responsible for the observed benefit, there was no direct evidence that this benefit was attributable to the "Q-ness" of the stimulus. In the present study, a subset of Rauschenberger and Yantis's experiments was repeated with Chinese subjects, who had never been exposed to the Latin alphabet. For these subjects, there was no benefit for the "Q"-like stimulus, in contrast to the results of Rauschenberger and Yantis's study. These results show that a simple $45^{\circ}$ rotation of a stimulus can affect search efficiency significantly - but only when this rotation bestows meaning, or familiarity, to that stimulus.
\end{abstract}

A now classic finding in the visual search literature is that a circle with an intersecting line is found more efficiently among circles without a line than is a circle without a line among circles with a line (see Figure 1). This experiment, which was reported by Treisman and Souther (1985, Experiment 1), is ubiquitously described as "Qs among Os” (e.g., Pashler, 1998, p. 139; Treisman, 1990, 1996; VanRullen \& Koch, 2005; Wolfe, 2001). However, in the original experiment, the intersecting lines were not slanted, as they would be in a "Q," but rather, they were vertical (see Figure 1). Rauschenberger and Yantis (2006) replicated Treisman and Souther's findings very closely using vertical lines. However, when they rotated the circle-line stimuli to correspond to the orientation of a "Q," the difference in search efficiency between the two display compositions was much attenuated, and search for the circle among circle-line combinations became significantly more efficient than before (see Figure 2). The same increase in search efficiency was not observed when the (vertically oriented) circle-line stimulus was rotated by $225^{\circ}$, so that it corresponded to an inverted, mirrorreversed "Q." Importantly, the latter transformation preserved the $45^{\circ}$ orientation of the line in the circle-line

This research was supported by NSF Grant 0418179 to R.R. We express our gratitude to the subjects in our experiments, who took time out of their busy lives during the particularly demanding harvesting season to help us out with our study. We also thank Eyal Reingold, Jim Hoffman, and one anonymous reviewer for their helpful comments. Correspondence should be addressed to R. Rauschenberger, User Interface Design Center, Siemens Corporate Research, 755 College Road East, Princeton, NJ 08540 (e-mail: robert.rauschenberger@siemens.com). pair; the increase in search efficiency therefore cannot be attributed to any benefit potentially conferred by an oblique line orientation.

Although the comparison between the results for the oriented circle-line pairs at various orientations $\left(0^{\circ}, 45^{\circ}\right.$, or $225^{\circ}$ from vertical) is quite suggestive of the conclusion that the "Q-ness" of the $45^{\circ}$-rotated stimulus facilitated search, these experiments do not yet rule out the possibility that some stimulus factor other than the "Q-ness" of the one stimulus might have been responsible for the observed differences between experiments (see Shen \& Reingold, 2001). More direct evidence would be provided by a demonstration that the presumed benefit from the "Q-ness" of the $45^{\circ}$-rotated circle-line pair is eliminated for observers for whom this particular stimulus orientation has no special significance (i.e., a within-stimulus, rather than a between-stimulus, manipulation). Earlier studies of stimulus familiarity had manipulated the orientation (canonical vs. mirror reversed) of letters and shown that performance was superior for letters in their canonical orientation (e.g., Frith, 1974; Reicher, Snyder, \& Richards, 1976; Richards \& Reicher, 1978; Wang, Cavanagh, \& Green, 1994). This manipulation essentially corresponds to the stimulus rotation employed by Rauschenberger and Yantis (2006), with the subtle difference that the starting point for the earlier studies was a familiar stimulus that was rendered unfamiliar, whereas the starting point for Rauschenberger and Yantis's study was an unfamiliar stimulus that was, arguably, rendered familiar.

As Shen and Reingold (2001) have shown for experiments of this type, there may be featural differences between the canonically oriented (familiar) and rotated or 


\section{$0^{\circ}$ condition}

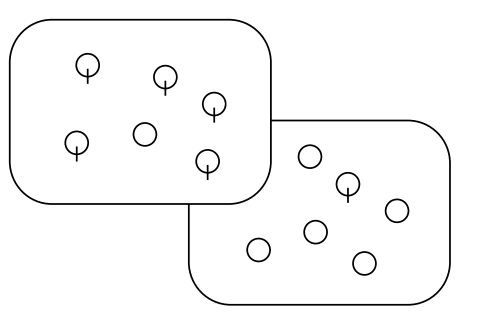

$45^{\circ}$ condition

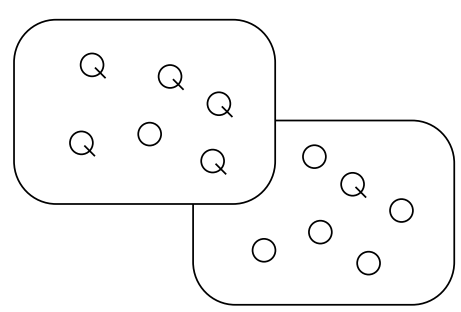

Figure 1. Examples of the displays for each condition. Only target-present conditions are shown.

reflected (unfamiliar) versions of a stimulus that drive the differences in search performance. A more promising approach therefore appears to be the manipulation of stimulus familiarity by the use of different subject groups, who are either familiar with a single unmanipulated stimulus or not (Malinowski \& Hübner, 2001; Shen \& Reingold, 2001). As an alternative, one might train observers to become familiar with a particular stimulus and then test to see whether there is any improvement in performance once familiarity has been achieved (e.g., Wang \& Cavanagh, 1993). However, this approach has the problem that it confounds familiarity with training on a specific search task, which, in and of itself, is sufficient to bring about enormous improvements in performance (e.g., Treisman, Vieira, \& Hayes, 1992).

For the present study, therefore, we opted to repeat the first two experiments from Rauschenberger and Yantis's
(2006) study - vertically oriented circle-line pair and $45^{\circ}$-rotated stimulus - with observers who had never been exposed to the characters of the Latin alphabet: subjects from a remote, rural setting in China (see the Method section). If the benefit enjoyed by the circle-line pair that resembles a "Q" is driven by its familiarity, there should be no such benefit for the Chinese subjects. That is, search should be inefficient for both the vertically oriented circle-line pair and the $45^{\circ}$-rotated version (and comparably so).

In a slight variation of Rauschenberger and Yantis (2006), the same subjects were used for both experiments. This additional within-subjects manipulation allows a more direct comparison between the two experiments (and greater statistical power, owing to the within-subjects design). It also permits an examination of order effects: For Western observers, who are familiar with the Latin alphabet, the
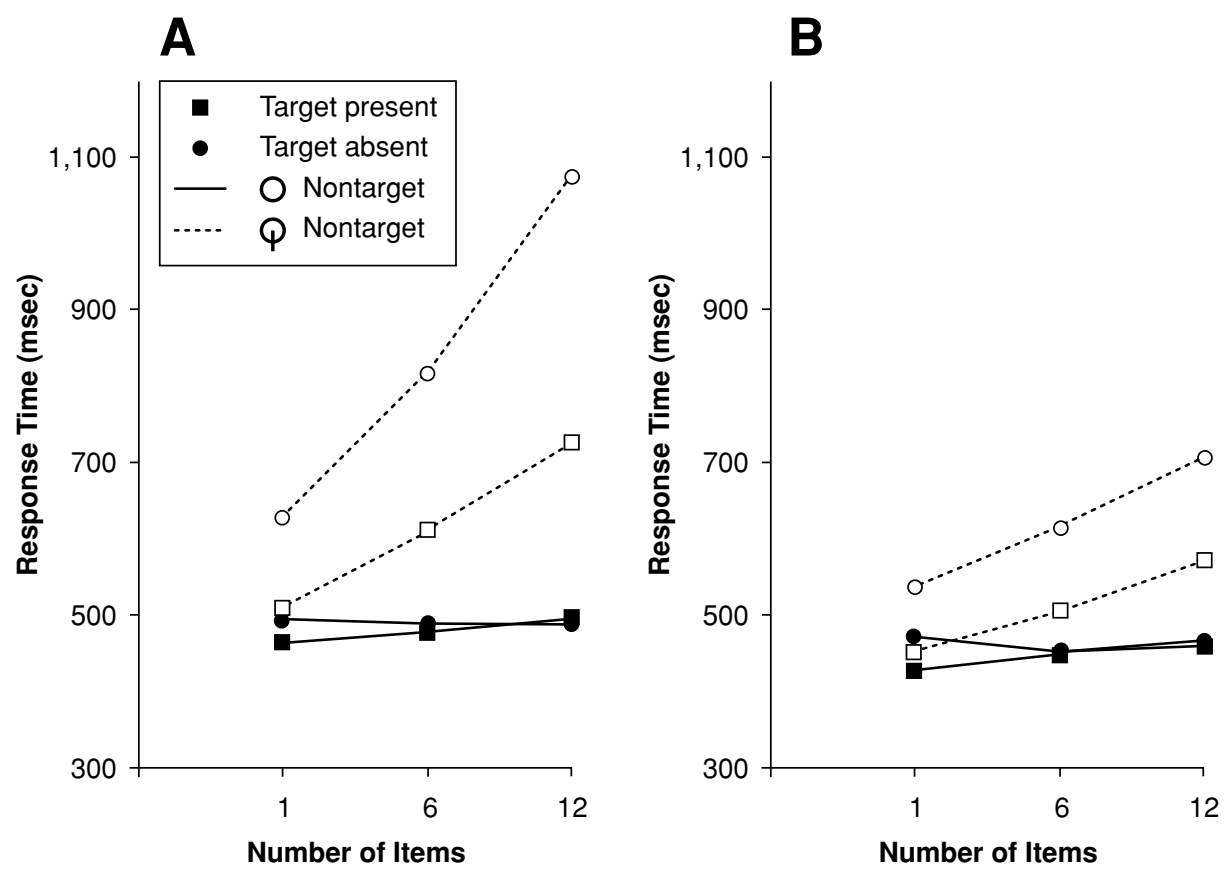

Figure 2. Results from Rauschenberger and Yantis (2006), for comparison with Figure 3. (Note that the scale differs from the one used in Figure 3.) 
within-subjects design was undesirable because prior exposure to the $45^{\circ}$-rotated circle-line stimulus might have led the subjects to persevere in an (implicit or explicit) "Q" interpretation of the stimulus if they received the $45^{\circ}$ rotation condition first (e.g., Epstein \& Rock, 1960). This perseveration would have introduced a considerable contamination. However, if the $45^{\circ}$-rotated version of the stimulus is entirely equivalent to the vertically oriented circle-line combination for non-Western observers, the order of presentation should make no difference. To anticipate the outcome of the following experiments, there were no significant order effects. ${ }^{1}$ Condition order will, therefore, be ignored as a factor in the following.

\section{METHOD}

\section{Subjects}

Twenty-one subjects ( 9 of them male, 12 female) between 28 and 50 years of age $(M=39.6 \pm 5.8$ years $)$ participated in this study. For their participation, they received gifts in the form of food items (in accordance with local custom). The subjects gave informed consent prior to participation and were fully debriefed following the experiment. All the subjects were selected on the basis of their complete lack of experience with the Latin alphabet. In order to obtain subjects who met this criterion, volunteers were recruited from a remote, highly rural region in China that has seen little or no exposure to Western culture (see immediately below).

\section{Geographic Location}

The experiment was conducted in Yuexi county in the Anhui ("Peaceful Emblem") Province of China. The Anhio Province is located approximately 400 miles west of Shanghai. The first road connecting the county's principal town to the outside world was not constructed until 1957, and even during the time the present study was conducted, road construction and hazardous driving conditions made it difficult to reach some of the villages from which our subjects were recruited. The first high school was not established until 1963 , making it relatively easy to find subjects who had not been exposed to the Latin alphabet in this region still plagued by high illiteracy rates, although such subjects are increasingly confined to particular (older) age cohorts.

\section{Stimuli and Equipment}

The displays consisted of a varying number of circles with or without an intersecting line. Each circle measured $1.4^{\circ}$ (of visual angle) in diameter, and the lines were $1.0^{\circ}$ in length. For the $0^{\circ}$ stimulus, the lines were oriented vertically and intersected the circles in the bottom center, extending $0.5^{\circ}$ above and below the point of intersection. In the $45^{\circ}$ condition, the same stimulus was rotated by $45^{\circ}$ counterclockwise (to resemble a "Q"). The stimuli were black on a white background.

All the stimuli were presented on a laptop computer with a 14.1-in. LCD display set to $1,024 \times 768$ pixel resolution and were freely viewed from a distance of roughly $35 \mathrm{~cm}$ (which corresponds to a comfortable typing/viewing distance for a laptop). Stimulus presentation was controlled by a custom-written program. The subjects made responses using the laptop keyboard. The "Z" key served as the target-absent response key, and the "/" key served as the targetpresent response key. The subjects were seated in a quiet, darkened room in a local government building.

\section{Design and Procedure}

The subjects performed six blocks of 72 trials each. Each block was preceded by a practice block of 15 trials. An experimental session lasted approximately $45 \mathrm{~min}$. On half of the trials, a target was present in the display; on the other half, there was no target present. There were 1,6 , or 12 items in each display, and all set sizes were presented equally often. Following the original design by Treisman and Souther (1985), the target occurred equally often in each of the four display quadrants (top left, top right, bottom left, or bottom right) and also equally often at each of three eccentricities (inner, middle, or outer). All other display items were presented in random locations, roughly evenly distributed across the display. The position of each item was determined offline for all the displays and then read in by the program executing the experiment. This procedure ensured that all the subjects received the same displays, albeit in a different order for each subject. The factorial combination of these factors resulted in $2 \times 3 \times 4 \times 3=72$ trials, which were presented in a fully mixed, randomized sequence. For half the blocks (either the first or the second half of the session), the target was a circle with an intersecting line; for the other half, it was a circle without a line. The other stimulus served as the nontarget in each case. The order of blocks was counterbalanced between subjects.

At the beginning of each block, the subjects were shown the target stimulus in the center of the screen, accompanied by a message that translates into the following: "This will be your target during the entire block” (在整个测试中, 这就是你所要寻找的东西); “ignore all the other items" (不要去看其他的东西). The subjects began the execution of the experiment by pressing the space bar. The space bar also allowed the subjects to resume the experiment when it paused following each practice block and after each experimental block (giving the subjects the opportunity to take a brief break).

During blocks, the experiment ran continuously. Each trial began with a blank screen containing only a fixation cross that was presented for $1,700 \mathrm{msec}$. Three hundred milliseconds before the onset of the search display, a $1000-\mathrm{Hz}$ tone alerted the subjects to the imminent appearance of the search display. The search display remained on until a response was issued. The response then triggered the next trial without delay.

The subjects were instructed to respond as quickly as possible while keeping errors to a minimum. If an error occurred, the computer provided auditory feedback in the form of a chime, and the error trial was reinserted at some later point in the same block. At the end of each block, the subjects received feedback on their overall performance on that block. If they made too many false alarms ( $>5 \%$ of the total number of trials on a given block), the program displayed a message that translates into the following: "A number of times, you said there was a target present when in fact there was no target” (有很多次目标没有出现, 但是你 错误的判断为它出 现了). If they had too many misses ( $>5 \%$ of the total number of trials), the program displayed a message that translates into the following: "A number of times, you said there was no target when in fact there was a target present” (有很多次目标确实出 现了，但是 你错误的判断为它没 有出现). The subjects were then instructed to “please slow down and make fewer errors" (请放慢你的判断速 度, 减少错误).

\section{RESULTS}

The results for the $0^{\circ}$ condition are shown in Figure $3 \mathrm{~A}$. Response times (RTs) increased markedly with set size when the nontargets were circle-line combinations (targetpresent slope, $36 \mathrm{msec} /$ item; target-absent slope, $96 \mathrm{msec} /$ item), but not when they were simple circles (target present slope, $5 \mathrm{msec} /$ item; target-absent slope, $1 \mathrm{msec} /$ item) $[F(2,40)=156.58, p \ll .001$, for the interaction of nontarget type and set size]. The same pattern of results was present in the error data $[F(2,40)=21.39, p<.001$, for the interaction between nontarget type and set size], which are provided in Table 1. There was, hence, no sign 

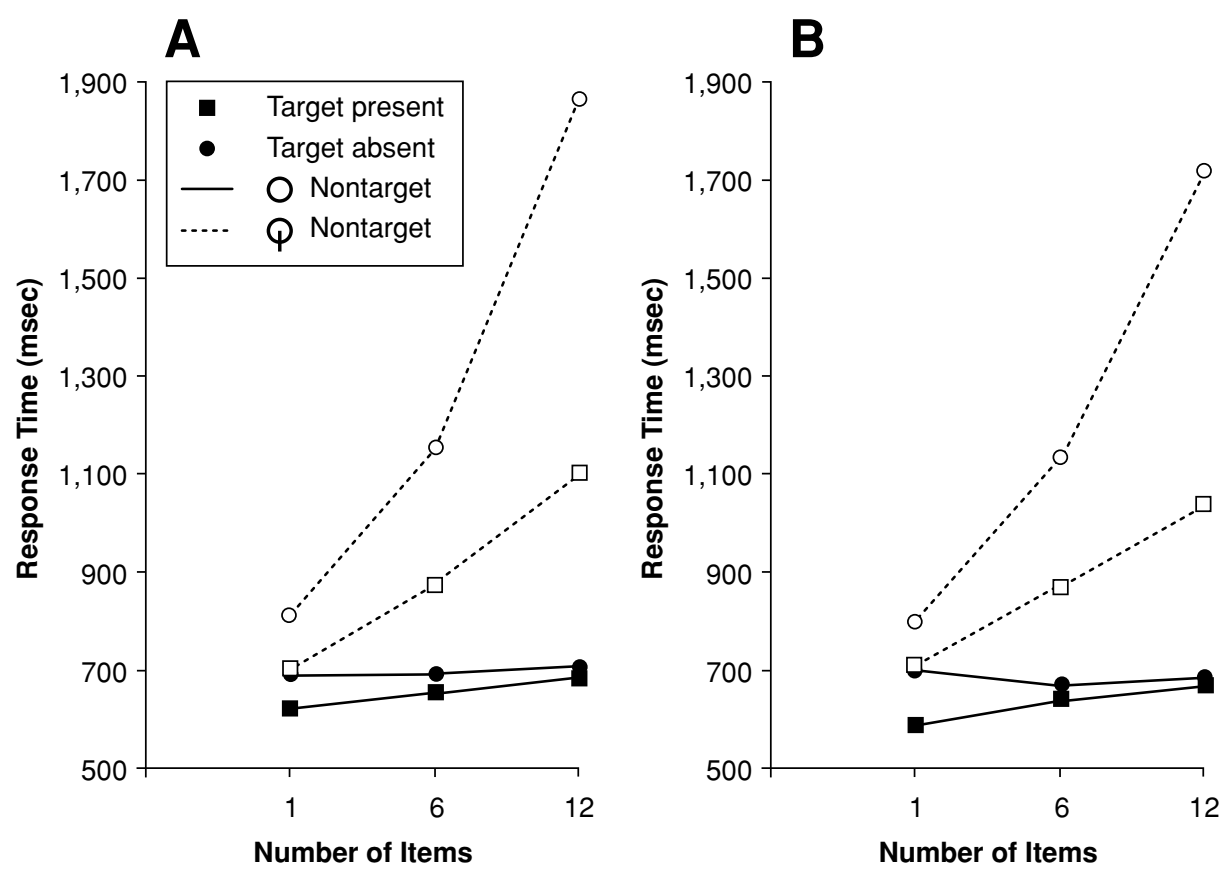

Figure 3. (A) Results from the $0^{\circ}$ condition: correct response times on target-present and targetabsent trials, respectively, at each set size. (B) Results from the $45^{\circ}$ condition.

of a speed-accuracy trade-off. These results essentially replicate those from two previous studies: Treisman and Souther (1985) and Rauschenberger and Yantis (2006). This replication is important because it demonstrates that sensible results can be obtained using subjects who have no experience with computers or, indeed, computer-based experiments. This fact is quite encouraging to anyone who might consider conducting cross-cultural visual perception experiments. Not only is it still possible to locate subjects who have never been exposed to the characters of the Latin alphabet, but also it is feasible to use these subjects in computer-based perception experiments and to compare their data with those of Western college students. The replication of previous results furthermore ensures that the $0^{\circ}$ condition provides a reasonable basis for comparison with the $45^{\circ}$ condition.

The results for the latter condition are shown in Figure $3 \mathrm{~B}$. As for the $0^{\circ}$ stimulus, RTs increased markedly with set size when the nontargets were circle-line combinations (target-present slope, $30 \mathrm{msec} /$ item; target-absent slope, $84 \mathrm{msec} / \mathrm{item})$, but not when they were simple

Table 1

Error Data for Experiments 1 and 2 in Percentage of Error

\begin{tabular}{llccccccc}
\hline & & \multicolumn{3}{c}{ Target Present } & & \multicolumn{3}{c}{ Target Absent } \\
\cline { 3 - 5 } \cline { 7 - 9 } & Nontarget & 1 & 6 & 12 & & 1 & 6 & 12 \\
\hline Experiment 1 & Circle & 0.4 & 1.6 & 1.4 & & 0.6 & 0.5 & 0.1 \\
& Circle-line & 0.6 & 2.9 & 8.9 & & 1.0 & 0.4 & 0.8 \\
Experiment 2 & Circle & 0.0 & 1.4 & 1.3 & & 0.5 & 0.3 & 0.1 \\
& Circle-line & 1.1 & 2.0 & 5.7 & & 1.5 & 0.3 & 0.3 \\
\hline
\end{tabular}

circles (target-present slope, $7 \mathrm{msec} /$ item; target-absent slope, $-1 \mathrm{msec} /$ item) $[F(2,40)=222.65, p<.001$, for the interaction of nontarget type and set size]. The same pattern of results was again present in the error data $[F(2,40)=3.58, p<.05$, for the interaction between nontarget type and set size], which are provided in Table 1. Hence, there was no sign of a speed-accuracy trade-off in Experiment 2 either.

\section{Comparison Between Conditions}

As can be seen from a comparison between Figures 3A and $3 \mathrm{~B}$, the results from the $0^{\circ}$ condition are quite similar to those from the $45^{\circ}$ condition. This similarity in results stands in contrast to the clear qualitative (and quantitative) differences obtained by Rauschenberger and Yantis (2006), using Western observers. To illustrate the strikingly different effects of stimulus rotation for Western and non-Western observers, Rauschenberger and Yantis's results are reproduced in Figure 2.

Statistical comparison between conditions confirmed the lack of an effect of stimulus rotation for non-Western observers: In an ANOVA with stimulus rotation, nontarget type, target presence, and set size as factors, none of the interactions involving stimulus rotation was significant $[F<1$ for the interactions with nontarget type and target presence, as well as for the three-way interaction with target presence and set size, and for the four-way interaction with nontarget type, target presence, and set size; $F(2,80)=1.87$, n.s., for the interaction with set size; $F(1,40)=1.10$, n.s., for the three-way interaction with nontarget type and target presence; $F(2,80)=2.57$, n.s., 
for the three-way interaction with nontarget type and set size], nor was the main effect of stimulus rotation significant $(F<1)$.

The lack of statistically significant effects clearly demonstrates that there is no benefit from the "Q-ness" of the stimulus for observers for whom the $45^{\circ}$ rotation of the circle-line combination carries no special meaning. In this regard, the results of the present study contrast strongly with those of Rauschenberger and Yantis's (2006) study, in which there was a clear qualitative difference in search performance for the two different orientations of the circle-line pair. The lack of a difference in the present study strongly suggests that featural differences between the two stimuli were unlikely to have contributed to the effect observed by Rauschenberger and Yantis. This conclusion can be made with particular confidence because stimulus type was manipulated within subjects.

Unfortunately, a direct comparison between the results of Rauschenberger and Yantis's (2006) study and the present study is not possible because the Chinese subjects performed worse (in terms of search efficiency and overall RT) than did the Western subjects. Such differences in performance should not be surprising, given that the Chinese subjects had never worked with computers, whereas the Western subjects, as students at a top American university, should have had ample experience using computers. (Presumably, they were also well practiced at computer games.)

\section{DISCUSSION}

There has been a long history of interest in the effects of familiarity on search performance, dating back over 30 years (e.g., Frith, 1974; Greene \& Rayner, 2001; Krueger, 1970; Lajoy \& Seethoff, 1974; Malinowski \& Hübner, 2001; Reicher et al., 1976; Richards \& Reicher, 1978; Shen \& Reingold, 2001; Wang \& Cavanagh, 1993; Wang et al., 1994). The most common approach to manipulating familiarity has been to rotate letters out of their canonical orientation, rendering them less familiar by this operation. Recently, however, it was discovered that manipulating a stimulus in this manner not only alters its familiarity, but also, potentially, introduces differences at the basic featural level (Shen \& Reingold, 2001). Alternatively, stimulus familiarity has been manipulated by training subjects on a particular set of stimuli in order to render these stimuli more familiar through repeated exposure. However, this approach is not unproblematic, because the training often confounded stimulus exposure with practice on a very particular search task (see, however, Lubow \& Kaplan, 1997, who cleverly avoided this confound).

Recently, investigators have sidestepped both of these issues by manipulating familiarity using subject groups with different - and ideally, mutually exclusive - linguistic backgrounds. A study by Shen and Reingold (2001), for example, compared performance of American and Chinese subjects on search using Chinese characters, which were familiar and meaningful to the Chinese subjects, but not to the American subjects. A related study by Malinowski and Hübner (2001) compared search performance of German and Slavic subjects. In that study, a particular letter stimulus (a mirror-reversed "N") was unfamiliar to one group of subjects (the Germans) but familiar to the other group of subjects in its - for the Latin alphabet - noncanonical mirror-reversed orientation. For the German subjects, search was efficient when the canonically oriented stimulus served as nontarget, but not when its mirror-reversed version served as nontarget. By contrast, search was efficient with both versions of the stimulus for the Slavic subjects.

The present study conceptually replicates Malinowski and Hübner's (2001): For the American subjects, search was efficient for the presumably familiar, "Q"-like circleline combination but inefficient for the same stimulus in a different orientation, whereas search was equally inefficient for both versions of the stimulus for the Chinese subjects. A search asymmetry present for one set of observers was absent for another set. In some respects, however, the present study constitutes the converse of Malinowski and Hübner's: Rather than rendering a particular unfamiliar stimulus familiar (and thereby abolishing an existing search asymmetry) by taking the stimulus to a group of subjects who had extensive experience with that stimulus, the present study rendered a "familiar" stimulus unfamiliar (and thereby reinstated a previously attenuated search asymmetry) by presenting it to a group of observers who had no experience with that stimulus. With the increasing dissemination of Western culture into the furthest reaches of civilization, it will become increasingly more difficult to conduct studies of this sort. The present study, however, demonstrates that for the time being, it is still feasible and useful to conduct cross-cultural experiments of the sort reported here.

\section{REFERENCES}

Epstein, W., \& Rock, I. (1960). Perceptual set as an artifact of recency. American Journal of Psychology, 73, 214-228.

FRITH, U. (1974). A curious effect with reversed letters explained by a theory of schema. Perception \& Psychophysics, 16, 113-116.

GreENE, H. H., \& RAYNER, K. (2001). Eye movements and familiarity effects in visual search. Vision Research, 41, 3763-3773.

Krueger, L. E. (1970). Search time in a redundant visual display. Journal of Experimental Psychology, 83, 391-399.

Lajoy, R. J., \& Seethoff, P. M. (1974). Effects of familiarity, verbal response, and practice on a visual search task. Perceptual \& Motor Skills, 38, 1311-1314.

LuBow, R. E., \& KAPLAN, O. (1997). Visual search as a function of type of prior experience with target and distractor. Journal of Experimental Psychology: Human Perception \& Performance, 23, 14-24.

MAlinowski, P., \& HüBNER, R. (2001). The effect of familiarity on visual-search performance: Evidence for learned basic features. Perception \& Psychophysics, 63, 458-463.

PASHLER, H. (1998). The psychology of attention. Cambridge, MA: MIT Press.

Rauschenberger, R., \& Yantis, S. (2006). Perceptual encoding efficiency in visual search. Journal of Experimental Psychology: General, 135, 116-131.

Reicher, G. M., Snyder, C. R. R., \& Richards, J. T. (1976). Familiarity of background characters in visual scanning. Journal of Experimental Psychology: Human Perception \& Performance, 2, 522-530. 
Richards, J. T., \& Reicher, G. M. (1978). The effect of background familiarity in visual search: An analysis of underlying factors. Perception \& Psychophysics, 23, 499-505.

Shen, J., \& ReIngold, E. M. (2001). Visual search asymmetry: The influence of stimulus familiarity and low-level features. Perception $\&$ Psychophysics, 63, 464-475.

Treisman, A. [M.] (1990). Features and objects in visual processing. In I. Rock (Ed.), The perceptual world: Readings from Scientific American magazine (pp. 97-110). New York: Freeman.

Treisman, A. [M.] (1996). The binding problem. Current Opinion in Neurobiology, 6, 171-178.

Treisman, A. [M.], \& Souther, J. (1985). Search asymmetry: A diagnostic for preattentive processing of separable features. Journal of Experimental Psychology: General, 114, 285-310.

Treisman, A. [M.], Vieira, A., \& HaYes, A. (1992). Automaticity and preattentive processing. American Journal of Psychology, 105, 341-362.

VAnRullen, R., \& KocH, C. (2005). Visual attention and visual awareness. In G. G. Celesia (Ed.), Handbook of clinical neurophysiology. Vol. 5. Disorders of visual processing (pp. 65-83). New York: Elsevier.
WANG, Q., \& CAVANAGH, P. (1993). Acquiring familiarity effects in visual search with Chinese characters. Investigative Ophthalmology \& Visual Science, 34, 1236.

Wang, Q., Cavanagh, P., \& Green, M. (1994). Familiarity and pop-out in visual search. Perception \& Psychophysics, 56, 495-500.

Wolfe, J. M. (2001). Asymmetries in visual search: An introduction. Perception \& Psychophysics, 63, 381-389.

\section{NOTE}

1. As determined by a mixed ANOVA with experiment and experiment order as between-subjects factors and nontarget type, target presence, and set size as within-subjects factors. All of the interactions involving experiment and/or experiment order were nonsignificant.

(Manuscript received January 25, 2005; revision accepted for publication August 8, 2005.) 